\title{
Formação continuada para o ensino de MATEMÁTICA: um estudo em Vilhena ${ }^{17}$
}

DOI: 10.23864/cpp-v1-n1-45

\section{Resumo}

O artigo apresenta a pesquisa realizada com professoras dos Anos Iniciais do município de Vilhena - RO que participaram de atividades de formação continuada propostas pelo projeto GETEMAT - Grupo de Estudo e Trabalho Pedagógico do Ensino de Matemática ${ }^{18}$. O objetivo foi analisar como as professoras consideraram as ações desenvolvidas durante sua participação o Projeto GETEMAT para a mudança de sua prática pedagógica. A partir de uma abordagem qualitativa, foram utilizados como instrumentos de coleta de dados: diário de campo das reuniões, relatos das professoras sobre as reuniões através de um memorial, e entrevista semiestruturada. O referencial teórico estudado privilegiou os autores da área de formação de docentes e Educação Matemática. Durante a coleta de dados foi possível testemunhar quão importante foi para os professores e professoras participarem de uma formação continuada através de um grupo de estudo, pois tiveram a oportunidade de questionar, expor suas dúvidas e angústias e, com o diálogo com os demais participantes, vivenciaram trocas de experiências e saberes que possivelmente irão refletir na sua prática em sala de aula.

Palavras-Chave. Formação inicial. Formação continuada. Ensino de matemática. Pesquisa-ação.

\footnotetext{
${ }^{17}$ Artigo elaborado a partir de uma monografia apresentada como requisito parcial de avaliação no curso de graduação em Pedagogia/2012, orientada pela terceira autora.

${ }_{18}$ Projeto de Pesquisa Financiado pelo CNPq Edital n ${ }^{0} 55 / 2008-C T$ Amazônia.
}

ISSN 2526-2882

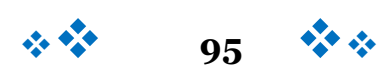




\title{
Continuing education the teaching of Mathematics: a study in Vilhena
}

\author{
Maria Candida Müller \\ Joélice Pederiva Barbosa \\ Juracy Machado Pacífico
}

\section{Abstract}

This paper presents a study of a group of teachers who attended a continuing education proposed by the project GETEMAT - Study Group and Educational Work of the Teaching of Mathematics. Aimed to analyze how the teachers of the early years of the public schools of Vilhena considered Project GETEMAT to change their practice. From a qualitative approach, were used as instruments of data collection: field diary of meetings, reports from teachers about the meetings, and semi-structured interview. The theoretical study authors focused in the area of teacher formation and and teaching mathematics. It was observed how important is for teachers participated in a continuing education through a study group, as well they had the opportunity to ask questions, express their doubts and fears and, in dialogue with others participant experiencing exchanged experiences and knowledge that will be reflected in practice in the classroom.

Keywords. Initial formation. Continuing education. Math education. Action research. 


\section{Primeiras ideias}

Há muitos estudos sobre formação continuada de professores (IMBERNÓN, 2009; NACARATO; MENGALI; PASSOS, 2009; CURI, 2005; BORBA, 2006), mas na prática não se percebe resultados significativos de mudança de postura pedagógica do professor.

Silva (2002) demonstra que uma formação continuada que traz resultado é aquela que ocorre dentro da própria escola, através de grupos de estudo, no qual os professores atuam e têm a oportunidade de refletir sobre suas práticas e juntos solucionarem os problemas de aprendizagem dos alunos. Este autor critica a formação continuada oferecida nos programas governamentais, nos quais os professores são meros ouvintes, nem ao menos são questionados sobre suas ideias e práticas, desenvolvendo uma temática específica dos conteúdos escolares ou sobre metodologias, sem considerar $\theta$-os professores realmente necessitam conhecer para repensar sua prática pedagógica.

Especificamente, com relação ao ensino de Matemática, percebe-se através dos resultados das pesquisas realizadas pelo antigo Saeb (Sistema de avaliação da educação básica) e atual Prova Brasil 2005 e 2007, as dificuldades que os alunos têm em relação a esta disciplina, sinal que também os professores não estão conseguindo proporcionar aos estudantes uma aprendizagem que resulte no entendimento dos conceitos trabalhados pela escola. Uma das formas de se reverter o quadro com relação ao desempenho dos alunos em Matemática possivelmente será com a formação continuada dos professores dos anos iniciais do ensino fundamental para o ensino desta disciplina.

As propostas de formação continuada geralmente propõem atualizações de conteúdos específicos e/ou metodologias de ensino que possibilitem a reflexão sobre a prática docente e possibilitem mudanças no processo de ensinar e aprender na educação básica. No entanto, a formação continuada em serviço professor possivelmente só terá resultado quando o próprio docente assumir um papel ativo neste processo, propondo discussões que efetivamente possibilitem uma reflexão sobre seu trabalho pedagógico e traga como consequência a descoberta de outras maneiras de ensinar e aprender, que acompanhem o desenvolvimento de teorias e estudos atuais sobre como se dá o processo ensino-aprendizagem dos discentes.

Assim, a pesquisa desenvolvida ao longo de três anos pelo Projeto GETEMAT (AUTOR, 2009, 2011) buscou dados que corroborassem a perspectiva de formação docente baseada na constituição de grupos de estudo colaborativo e cooperativo congregando docentes da educação básica dos anos iniciais, docentes da universidade e futuros professores e professores, estudantes do curso de Pedagogia.

Os dados apresentados neste artigo correspondem a um dos objetivos do Projeto GETEMAT que era avaliar junto aos docentes que participaram dos encontros do grupo a

ISSN 2526-2882

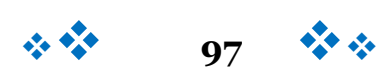


importância e eficácia deste tipo de formação em possíveis mudanças de sua prática pedagógica.

Nesse contexto o presente estudo objetivou analisar e anunciar as ações desenvolvidas pelo grupo de estudo colaborativo e cooperativo GETEMAT - Grupo de Estudo e Trabalho Pedagógico do Ensino de Matemática, para formação continuada a partir da perspectiva das professoras participantes.

\title{
A pesquisa
}

Esta investigação é uma pesquisa qualitativa, mais especificamente, um estudo de caso, que se define, segundo Lüdke e André (1986, p. 18-21)

\begin{abstract}
Os estudos de caso visam à descoberta. [...] O quadro teórico inicial servirá assim de esqueleto, de estrutura básica a partir da qual novos aspectos poderão ser detectados, novos elementos ou dimensões poderão ser acrescentados, na medida em que o estudo avance. [...] Os estudos de caso usam uma variedade de fontes de informação. [...] o pesquisador recorre a uma variedade de dados, coletados em diferentes momentos, em situações variadas e com uma variedade de tipos de informantes.
\end{abstract}

Os instrumentais de coleta de dados foram: entrevista semiestruturada com alguns dos participantes do GETEMAT-geral, diário de campo com os registros de cada reunião e memorial individual dos docentes produzidos no final dos encontros.

A pesquisa de campo foi realizada com as professoras que participaram do GETEMAT - geral, grupo que reunia docentes de várias escolas do município de Vilhena que tinham como ponto em comum a docência nos anos iniciais. O período de coleta dos dados foi do segundo semestre de 2009 ao segundo semestre de 2010.

Foram entrevistadas três professoras que participaram de dezesseis encontros do grupo GETEMAT. A entrevista semiestruturada foi realizada com um roteiro de quatorze questões. Para preservar a identidade das professoras entrevistadas, utilizou-se como identificação a letra inicial do primeiro nome.

O diário de campo foi escrito durante as dezesseis reuniões de formação do GETEMAT - geral. De acordo com Lüdke e André (1986, p. 30), “Os focos de observação nas abordagens qualitativas de pesquisa são determinados basicamente pelos propósitos específicos do estudo, que por sua vez derivam de um quadro teórico geral, traçado pelo pesquisador.”

Outro instrumental foi o memorial individual que cada professor elaborava ao final do encontro registrando suas observações sobre o que havia sido discutido, suas dúvidas e considerações. Segundo Nascimento (2010, p. 75-76) o memorial trata-se de uma 
autobiografia, é constituído de uma narrativa, que traz referência sobre a vida familiar, escolar e profissional, e muitas das vezes exigem crítica e autocritica.

O fato é que o memorial como instrumento auto formativo possibilita transformação de práticas profissionais a partir da reinvenção do si. Permite ainda a compreensão de si e de seus processos formativos a partir da própria escrita, o que proporciona a conquista de autonomia e auto - formação. (NASCIMENTO, 2010, p. 77)

Da mesma forma que na entrevista, os relatos preservam a identidade da autora, sendo referenciados pela letra inicial do primeiro nome.

Com esses instrumentos e os dados produzidos através deles, buscou-se identificar quais indícios são apresentados pelas docentes que participaram da pesquisa sobre mudanças em sua prática a partir da sua participação no grupo de estudo GETEMAT.

\section{Alguns indícios da pesquisa}

A seguir estão apontados alguns indícios encontrados nos dados construídos ao longo do desenvolvimento da pesquisa. Procurou-se agrupar em categorias que representam as principais preocupações deste trabalho ao fazer a avaliação do projeto GETEMAT junto às docentes que participaram do grupo de estudo colaborativo GETEMAT-geral.

É importante esclarecer que o Projeto GETEMAT, enquanto projeto de pesquisa se encerou em dezembro de 2011, no entanto, o grupo de estudo colaborativo GETEMAT ainda se reúne até a presente data.

\section{Percepção das professoras sobre a metodologia utilizada no projeto GETEMAT}

O projeto GETEMAT teve como metodologia da pesquisa-ação. Segundo Thiollent (1996), a pesquisa-ação é uma estratégia metodológica na qual há uma ampla e explícita interação entre pesquisadores e pessoas implicadas na situação investigada.

Nessa perspectiva, a principal ação do projeto foi a constituição de um grupo de estudo colaborativo (FIORENTINI, 2004) denominado GETEMAT - Grupo de Estudo e Trabalho Pedagógico para o Ensino de Matemática, que continuou se reunindo mesmo após o término do projeto de pesquisa, constituindo-se em uma comunidade de aprendizagem do professor de acordo com Cochran-Smith e Lytle (1993). O primeiro grupo de estudo era constituído, como já informado, por docentes de diferentes escolas, como no desenvolvimento do projeto de 
pesquisa, constituiu-se um grupo em uma única escola, passou-se a denominar GETMAT-geral este primeiro grupo do qual as participantes da pesquisa fizeram parte.

Uma primeira preocupação do GETEMAT-geral foi criar um vínculo de confiança com as professoras e professores que participavam do grupo de estudo. Pimenta (2005, p. 535) aponta que no processo de realização de uma pesquisa-ação tem-se:

Mediante a reflexão colaborativa, os professores se tornaram capazes de problematizar, analisar e compreender suas próprias práticas, de produzir significado e conhecimento que lhes possibilitou orientar o processo de transformações das práticas escolares, gerando mudanças na cultura escolar, criando comunidades de análise de investigação, crescimento pessoal, compromisso profissional e práticas organizacionais participativas e democráticas.

A pesquisa-ação faz com que os pesquisadores tenham que desempenhar um papel ativo na própria realidade do fato observado. Através da entrevista, observação e relato das professoras no memorial foi possível detectar que a metodologia da pesquisa-ação foi realmente utilizada:

[...] Normalmente não costumo participar das discussões que são realizadas nos cursos, mas hoje me senti à vontade para fazê-lo. Talvez pelo fato de sermos em poucas pessoas, isso me tenha feito sentir segura para falar. Percebi que minhas colegas também possuem dificuldades para ensinar determinado conteúdo e isso de certa forma trás em alivio por pensar que não apenas eu estou precisando de ajuda. [...] É gratificante como professora saber que alguém se preocupa com minha formação continuada. (MEMORIAL Profa.E)

[...] Acredito que quando fazemos à relação reflexão e ação, temos mais chance de colhermos frutos positivos desse trabalho. (MEMORIAL - Profa. L)

[...] Refletir sobre a prática pedagógica, ser instruído a prosseguir e oferecer algo melhor para os alunos superarem os desafios, foi o que mais me chamou atenção neste encontro. Sugiro que a metodologia continue. (MEMORIAL Profa. EL)

[...] estamos caminhando para um aprimoramento no ensino de matemática. (MEMORIAL - Profa. A)

Nota-se a partir dos depoimentos destacados sobre a proposta do grupo GETEMATgeral que um processo de formação continuada de professores que se limita a uma simples descrição da situação ou uma avaliação do rendimento escolar, é insuficiente para solucionar os problemas da situação da educação atual, mas a proposta da pesquisa-ação no processo de formação continuada se difere pelo aspecto de focalizar ações ou transformações específicas.

Durante uma das reuniões, uma professora relatou que alguém tinha que dar essa possibilidade de refletirem sobre a prática, pois elas ensinavam diferente, com uma abordagem muito abstrata para o entendimento dos alunos. Utilizavam basicamente continhas, ou seja, 
trabalham com as operações de uma forma descontextualizada. No entanto, a partir das discussões nas reuniões do GETEMAT - geral, havia aprendido e compreendido outras maneiras de ensinar seus alunos.

A coordenadora do projeto GETEMAT durante as reuniões questionava as participantes sobre vários assuntos em relação ao ensino de Matemática, principalmente sobre a sua formação inicial e como ensinar as crianças hoje em dia. Todos os questionamentos tinham um objetivo, dar oportunidades para as professoras refletirem sobre sua prática.

\section{Discussões sobre a formação de professores e políticas públicas}

$\mathrm{Na}$ análise do diário de campo observou-se que a discussão sobre a formação do professor para atuar nas aulas de matemática e as políticas públicas para esta formação foram constantes nos encontros.

Uma das professoras relatou que na faculdade e no curso de magistério estudaram vários conteúdos de matemática, mas que quando se está lecionando a realidade é outra. $\mathrm{Ou}$ seja, a formação inicial não foi suficiente para o trabalho pedagógico com os alunos, daí a necessidade de haver momentos para a formação continuada dos professores.

Outra professora também relatou que o sucesso da aula de matemática na sala de aula depende do professor, se ele gostar de Matemática ele passará uma ideia positiva em relação a ela, caso contrário o aluno não conseguirá aprender, pois achará difícil.

É importante lembrar que a maioria dos conhecimentos matemáticos que o educador possui é o mesmo que foi adquirido nas séries iniciais e outros de formação continuada que às vezes não atende as necessidades do professor. (MEMORIAL - Profa. Lu)

Quanto mais nos aprofundamos na matemática mais encantada eu fico com as várias formas existentes de explicar um mesmo assunto. [...] se tivéssemos acesso a materiais concretos para a exploração, não teríamos tanta dificuldade na compreensão da matemática, quando ainda estudávamos. Percebi também que algumas colegas não compreendem esse processo de dezena e unidade, mas sentem vergonha de perguntar [...]. (MEMORIAL - anônimo)

Aprendi coisas que até hoje não sabia. (MEMORIAL - anônimo)

Em um dos encontros as professoras questionaram a coordenadora, que também é professora do curso de Pedagogia, se na faculdade ela também ensinava às acadêmicas como trabalhar com as crianças visando o uso do material concreto e situações problemas, pois elas não tiveram essa oportunidade na formação inicial.

As próprias professoras concordaram que a maioria dos professores é resistente à mudança. E esta característica é um entrave para que os cursos de formação continuada 
produzam efeito na sala de aula. Segundo elas, muitas professoras participam de um curso somente com a intenção de confirmar a sua prática e poucas procuram novas formas de trabalhar o mesmo conteúdo com os alunos.

Além disto, observam que a grande maioria das professoras que participam de cursos de formação se vê algo novo, geralmente ignora e continua a trabalhar na forma tradicional.

Por isso, na discussão chegou-se a seguinte conclusão: para que se possa desenvolver um bom trabalho, sem ser criticado, é necessário um planejamento coletivo na escola com a coordenação pedagógica, no qual todos procuram seguir uma mesma linha de pensamento, desenvolvendo atividades pedagógicas que se complementam.

Outra questão relatada por uma das professoras durante os encontros foi o fato de que os professores são formados em diferentes instituições e por conta disto tem diferentes ideias e perspectivas sobre o trabalho na escola. Além disto, afirmam que não há ninguém no sistema de ensino municipal que coordena e ajuda os professores a desenvolverem um trabalho mais coeso. Alguns relatos das entrevistas corroboram esta afirmação:

A formação que eu tive em matemática ela foi mais dada do $5^{\circ}$ ao $6^{\circ}$ ano, eu tive muito pouco contato com os conteúdos e conceitos de séries iniciais da matemática, a gente trabalhava mais, o professor que a gente tinha no Magistério ele trabalhava muito os conteúdos mais de $6^{\circ}$ ao $9^{\circ}$ ano hoje, mas assim das séries iniciais não. (ENTREVISTA - Profa. H)

A minha formação inicial ela era, eu sou da época que se faziam logo os dois, eu estudava os conteúdos em casa e fazia a avaliação, para eu conseguir o certificado, de magistério, então aquilo não me deu base nenhuma. O que me deu base foi quando entrei na faculdade, comecei a ler livros e comecei a fazer essas relações, o que um autor falava o que o outro falava, como as crianças precisam saber, então foi com longo tempo que eu estou trabalhando e agora com essas formações é que tem melhorado ainda para eu atender essas crianças [...] eu não fiz disciplina de Matemática, tenho metodologia, mas não relacionada à Matemática. (ENTREVISTA - Profa. M)

Na minha época já havia a disciplina de Didática da Matemática, mas ela não me deu embasamento teórico para eu trabalhar com as crianças, então senti muitas dificuldades em relação a isso. (ENTREVISTA - Profa. E )

Foi sugerido por uma das professoras participantes que quando acabar o período do projeto, que se continuassem os encontros nas próprias escolas em que trabalham e se implantasse uma formação continuada permanente. Desta forma, as reuniões se ampliariam e abrangeriam todos os professores da escola, todos iriam participar e possivelmente melhorariam o ensino de matemática. Esta observação reforça a importância do desenvolvimento de proposta de formação na perspectiva da pesquisa-ação.

O registro das reuniões realizado no diário de campo apresenta como uma constante nas discussões dos diversos encontros, críticas das participantes em relação às propostas de avaliação e promoção vigentes no sistema educacional. Segundo elas, estas propostas não 
permitem um grande número de reprovações e com isso as crianças chegam no $6^{\circ}$ ano com muitas dificuldades em Matemática. Ou seja, as docentes que participavam dos encontros, a princípio, consideram o processo de avaliação como sendo a causa das dificuldades que os estudantes apresentam e não o trabalho pedagógico efetivamente desenvolvido nas escolas. Isso demonstra a necessidade de possibilitar aos docentes momentos de reflexão sobre sua prática, para que efetivamente possam perceber a relação existente entre sua prática e as possibilidades de aprendizagem dos seus alunos.

A partir das discussões, percebe-se que há uma grande preocupação do professor em cumprir o currículo elaborado pelo sistema de ensino municipal. Este seria um dos obstáculos para mudanças, porque, segundo as participantes, há o receio de inovar nas aulas com metodologias que envolvem mais tempo como, por exemplo, o uso de material concreto e situações problemas, onde o aluno participa de uma forma mais ativa no seu processo de aprendizagem.

\section{Atitudes das professoras em relação à Matemática}

Durante o desenvolvimento das reuniões do GETEMAT-geral pode-se observar, a partir do diário de campo e dos relatos das professoras uma mudança de atitude com relação à Matemática.

O encontro de hoje trouxe várias formas de trabalhar o campo multiplicativo que eu ainda não conhecia e si fiz em sala foi de forma mecânica sem possibilitar aos meus alunos a utilizar o raciocínio lógico. (MEMORIAL Profa. RO)

A aula de hoje me fez perceber o quanto eu estava enganada com a matemática, sempre pensei que só existia uma forma de fazer a divisão. E estou trabalhando esse conteúdo com os meus alunos de $4^{\circ}$ ano e eles tem muita dificuldade para compreender a sua lógica da maneira que eu estava ensinando. Quem sabe agora com essas outras possibilidades que eu aprendi nessa aula de hoje. (MEMORIAL - Profa. RE)

Observa-se pelos relatos acima que as professoras começam a perceber que os alunos já possuem um conhecimento prévio em relação à Matemática, mas que é preciso problematizá-los, ou seja, provocar um desequilíbrio para torná-los capazes de resolver situações mais complexas dominando a linguagem Matemática, a naturezas das técnicas operatórias e o cálculo mental.

[...] o professor tem que desconstruir crenças ou filosofias pessoais para que possa repassar aos alunos que estudar matemática não é um bicho de sete cabeças, mas, um processo que com atividades diversificadas, divertidas, desafiadoras podemos aprender, sem decorar e o melhor: não esquecer com o tempo (MEMORIAL - anônimo). 
As professoras se deram conta que ensinar a Matemática hoje de forma tradicional não está dando certo, os alunos estão mais questionadores, sendo necessárias estratégias e problematização para um ensino eficaz ou seja, o ensino que privilegia a memorização de algoritmos, sem sentido e significado para os alunos, precisa se substituído por um ensino que busca construir os conceitos a partir de ambientes de aprendizagem que tem como ponto principal o diálogo, a busca de soluções que efetivamente possibilitem ao aluno a aplicação dos conteúdos matemáticos escolares. Valoriza-se o ensino construtivista que visa no ensino a ação dos alunos, ou seja, para ele aprender é necessário ele manusear os objetos, utiliza-se um método ativo, o conhecimento deve ser construído obedecendo cada etapa dos estágios descrito pelas pesquisas realizadas por Piaget.

Estes pequenos indícios de mudança na prática das professoras envolvidas reforçam a proposta de formação através de grupos de estudo e reflexão, pois o encontro contínuo, a troca de experiências tanto positivas quanto das que não deram certo, possibilita ao professor um repensar de sua prática e a busca de outros caminhos para seu trabalho, seja a partir do estudo de um texto teórico ou da utilização de uma ideia proposta por um colega para o desenvolvimento de determinado conteúdo.

\section{Avaliação das professoras em relação ao GETEMAT}

Em várias reuniões as participantes relataram que fizeram algumas das atividades propostas na reunião anterior e que tiveram resultados satisfatórios.

Durante a última reunião de 2009, uma professora relatou que ela agora trabalha muitas situações problemas e enquanto uns ainda desenhavam para resolver o problema, outros já faziam mentalmente, ou seja, cada um estava construindo uma estratégia aceitável. Relatos assim podemos observar na íntegra logo abaixo:

O importante é que ele chegou a um resultado. Precisamos realmente criar o hábito de formar grupos de estudo. (MEMORIAL - Profa. Lu)

O encontro de hoje trouxe várias formas de trabalhar o campo multiplicativo que eu ainda não conhecia e si fiz em sala foi de forma mecânica sem possibilitar aos meus alunos a utilizar o raciocínio lógico. (MEMORIAL anônimo)

O encontro foi muito esclarecedor e mostra-me novos caminhos para eu trabalhar com meus alunos. Cada novo encontro as minhas expectativas são superadas. (MEMORIAL - anônimo)

O encontro foi ótimo. Esclareceu muitas dúvidas e também foram sugeridas muitas outras opções que poderei pôr em prática em sala de aula. (MEMORIAL - Profa. Ro) 
Na reunião algumas professoras relatam experiências em que tiveram na sala de aula usando materiais concretos, sempre visam resultados positivos e satisfatórios na aprendizagem dos alunos, e também dificuldades principalmente por não dominar o conteúdo envolvendo o uso desses materiais e também por muitas das vezes haver pouco material para grande quantidade de crianças em sala de aula.

\section{Para concluir}

A investigação realizada testemunha a eficácia da formação continuada em serviço defendida por Silva (2002), ou seja, a que privilegia a formação em grupos de estudo, tendo como estratégias aquelas propostas pela pesquisa-ação.

Os dados revelaram que as professoras que participaram do GETEMAT-geral mesmo diante de sua dificuldade em trabalhar alguns conteúdos de Matemática, sentiram dispostas e falar sobre isso e tirar suas dúvidas, ou seja, elas sentiram mais à vontade para questionar e aprender novas maneiras e ensinar os conteúdos de forma mais construtiva.

Pode-se perceber durante os encontros do grupo de estudo colaborativo que as professoras colaboradoras da pesquisa estavam aprendendo e percebendo que era possível tornar suas aulas de matemática mais proveitosas e prazerosas. Os relatos indicam que esta percepção, a princípio visual de quem estava participando do encontro também pode ser encontrada nos registros escritos das professoras.

Como resultado desse estudo espera-se contribuir para a literatura sobre formação continuada de docentes, apresentando a proposta de formação continuada em serviço em grupos de estudo colaborativo como uma alternativa viável e eficaz para a discussão e reflexão da prática docente, especialmente com relação ao ensinar e aprender Matemática nos anos iniciais.

\section{Referências}

BORBA, M.C. (org.). Tendências internacionais em formação de professores de matemática. Belo Horizonte: Autêntica, 2006.

COCHRAN-SMITH, M.; LYTLE, S. L. Inside/Outside: teacher research ad knowledge. New York: Teachers College Press, 1993.

CURI, Edda. A matemática e os professores dos anos iniciais. São Paulo: Musa, 2005. 
FIORENTINI, D. Pesquisar práticas colaborativas ou pesquisar colaborativamente? In: Borba, M. (org.) Pesquisa qualitativa em Educação Matemática. Belo Horizonte: Autêntica, 2004. 106P. 47-76.

IMBÉRNON, Francisco. Formação permanente do professorado: novas tendências. São Paulo: Cortez, 2009.

LUDKE, Menga. ANDRÉ, Marli. Pesquisa em Educação: abordagens qualitativas. São Paulo: EPU,1986.

MÜLLER, Maria Cândida - AUTOR. GETEMAT - Grupo de Estudo e Trabalho Pedagógico de Ensino de Matemática: Formação Continuada de Professores dos Anos Iniciais Para o Ensino de Matemática. In: CONGRESSO DE LEITURA DO BRASIL, 17, 2009, Campinas. Anais do $17^{\circ}$ COLE, Campinas, SP: ALB, 2009. Disponível em: http://www.alb.com.br/portal.html. Acesso em: o9 de fev. 2010. ISSN: 2175-0939.

. Formação Continuada de docentes dos anos iniciais: a proposta do GETEMAT. In: Anais XIII CONFERÊNCIA INTERAMERICANA DE EDUCAÇÃO MATEMÁTICA. 2011, Recife. Disponível em: http://www.cimm.ucr.ac.cr/ocs/index.php/xiii_ciaem/xiii_ciaem/paper/view/374. Acesso em 10 de out. 2011.

NACARATO, A. M; MENGALI, B. L; PASSOS, C. L. B. A Matemática nos anos iniciais do ensino fundamental: tecendo fios de ensinar e de aprender. Belo Horizonte: Autêntica, 2009.p. 15-38.

NASCIMENTO, Gilcilene Lélia Souza do. Memorial de formação: um dispositivo de pesquisa-ação-formação. Natal, RN. Universidade Federal do Rio Grande do Norte: 2010. Disponível em http://bdtd.bczm.ufrn.br/tedesimplificado/tde_arquivos/9/TDE-2011-02o9To43742Z-3275/Publico/GilcileneLSN_DISSERT.pdf, acesso em 21 de abril de 2012.

PIMENTA, Selma Garrido. Pesquisa-ação crítico-colaborativa: construindo seu significado a partir de experiências com a formação docente. Educação e Pesquisa, São Paulo, v. 31, n. 3, p. 521-539, set./dez. 2005.

SILVA, Moacir. A formação do professor centrada na escola: uma introdução. São Paulo: EDUC.2002.

THIOLLENT, Michel. Metodologia da Pesquisa-ação. São Paulo: Cortez, 1996. 


\section{Biografia Resumida}

Maria Candida Müller - Pós Doutora e Doutora em Educação pela Universidade Estadual de Campinas. Professora do Departamento Acadêmico de Ciências da Educação da Universidade Federal de Rondônia- UNIR/Campus de Vilhena. Docente do Programa de Pós-Graduação em Educação Escolar - Mestrado Profissional, PPGEE/MEPE/UNIR. Líder do Grupo de Pesquisa GEP - Grupo de Estudos Pedagógicos.

Currículo Lattes: http://lattes.cnpq.br/9997935968998147

Contato: maria.candida@unir.br

Joélice Pederiva Barbosa - Graduada em Pedagogia pela Universidade Federal de Rondônia/Campus de Porto Velho. Bolsistas de Iniciação Científica do CNPq, através do Projeto de Pesquisa GETEMAT financiado pelo CNPq - Edital $\mathrm{n}^{0} 55-\mathrm{CT}-$ Amazônia - Processo n ${ }^{0}$ 575443/2008-1.

Contato: jopederiva@hotmail.com

Juracy Machado Pacífico - Doutora em Educação Escolar/UNESP. Professora do Departamento de Ciências da Educação da Fundação Universidade Federal de Rondônia (UNIR). Coordenadora Adjunta e Professora do Programa de Pós-Graduação em Educação Escolar - Mestrado Profissional, PPGEE/MEPE/UNIR.

Currículo Lattes: http://lattes.cnpq.br/3051710228899281

Contato: juracypacifico@unir 